\title{
Development and verification of fingerprinting probes for Candida glabrata
}

\author{
Shawn R. Lockhart, ${ }^{1}$ Sophie Joly, ${ }^{1}$ Claude Pujol, ${ }^{1}$ Jack D. Sobel, ${ }^{3}$ \\ Michael A. Pfaller ${ }^{2}$ and David R. Soll ${ }^{1}$
}

Author for correspondence: David R. Soll. Tel: +1 319335 1117. Fax: +1 3193352772.

e-mail: drs@biovax.biology.uiowa.edu

1,2 Department of Biological Sciences ${ }^{1}$ and Pathology ${ }^{2}$ University of lowa, lowa City, IA 52242, USA

3 Department of Internal Medicine, Wayne State University, Detroit, MI 48201, USA

\begin{abstract}
Since Candida glabrata has emerged as one of the most common Candida pathogens, DNA probes have been developed which fulfil the requirements for effective fingerprinting. Using a screen for complex genomic fragments containing moderately repetitive sequences, seven DNA probes were cloned which generate complex Southern blot hybridization patterns with EcoRIdigested C. glabrata DNA. All of the probes are species-specific and the majority cross-hybridize to varying degrees. The capacity of two of the probes, Cg6 and Cg12, to measure genetic distance between independent isolates is verified by comparing clustering in dendrograms based on similarity coefficients computed between all pairs of 39 independent isolates fingerprinted with Cg6, Cg12 and randomly amplified polymorphic DNA. The capacity of the probes $\mathrm{Cg} 6$ and $\mathrm{Cg} 12$ to assess microevolution in clonal populations of infecting $C$. glabrata over time is also demonstrated. These probes can now be used in large computer-assisted epidemiological studies.
\end{abstract}

Keywords: DNA fingerprinting, Candida glabrata, RAPD verification

\section{INTRODUCTION}

Candida glabrata is one of the most common Candida species isolated from humans and one of the most common causes of nosocomial infections (Pfaller, 1996; Beck-Sague, 1993; Hazen, 1995; Voss et al., 1996; Nguyen et al., 1996). In a recent study of carriage in the oral cavity of individuals over 65 years of age in Iowa City, IA, USA, C. glabrata was found to be the most common commensal after Candida albicans, and when present, was found to colonize at densities higher, on average, than C. albicans (S. R. Lockhart and others, unpublished). C. glabrata has also emerged in recent years as one of the major causes of vaginal candidiasis (Sobel, 1996; Spinillo et al., 1995). To investigate the epidemiology of this pathogen, it is imperative that DNA fingerprinting methods be developed that can assess genetic distance between independent isolates in broad epidemiological studies, that can assess microevolution within clonal populations colonizing a particular anatomical locale over time, and that are readily amenable to computer-assisted analysis for generating large databases for retrospective studies.

Abbreviations: $\mathrm{CHEF}$ electrophoresis, contour-clamped homogeneous electric field electrophoresis; RAPD, randomly amplified polymorphic DNA.
Several DNA-based methods have been used to discriminate C. glabrata from other species, and they include randomly amplified polymorphic DNA (RAPD) (Lehmann et al., 1992), PCR of 18S rDNA (Maiwald $e t$ al., 1994), PCR of L1A1 (Burgener-Kairuz et al., 1994), PCR of a chitin-synthase-specific fragment (Jordan, 1994) and Southern blot hybridization with a radiolabelled actin gene (Mason et al., 1987). Several DNA methods have also been used to discriminate between isolates within this species, and they include restriction enzyme polymorphism (Vazquez et al., 1993), oligonucleotide fingerprinting (Sullivan et al., 1993), electrophoretic karyotyping (Asakura et al., 1991; Khattak et al., 1992; Kaufmann \& Merz, 1989; Vazquez et al., 1993) and RAPD (Lehmann $e$ t al., 1992). Although all of these methods are potentially effective in fingerprinting C. glabrata, none of them has been tested for their capacity to measure genetic distance between independent isolates, for their capacity to measure microevolution in clonal populations over time, or for their applicability to computer-assisted analysis and the genesis of a database.

An effective fingerprinting strategy should fulfil a number of requirements (Soll, 1993; Joly et al., 1996; Pujol et al., 1997). First, the capacity of a fingerprinting method to measure the genetic distance between unrelated, moderately related and highly related strains 
within a species must be verified through comparison with a second, independent fingerprinting method (Lockhart et al., 1996; Joly et al., 1996; Pujol et al., 1997). Second, the data for a particular isolate, usually in the form of a banding pattern, should be highly reproducible. Third, if the data provided by a method are in the form of banding patterns, the patterns should be of high enough contrast and the bands separated sufficiently for automatic computer-assisted analysis (Soll, 1993; Pujol et al., 1997). Fourth, the banding pattern or data generated by the method should be complex enough for the computation of meaningful similarity coefficients between isolates, so that dendrograms can be generated based on these coefficients for large sample sizes. Fifth, a method should provide some measure of microevolution within a clonal population over a reasonable time frame (Scherer \& Stevens, 1988; Schmid et al., 1993; Schröppel et al., 1994; Lockhart et al., 1995, 1996; Joly et al., 1996). To this end, we previously developed fingerprinting methods for $C$. albicans (Lockhart et al., 1996; Pujol et al., 1997), Candida tropicalis (Joly et al., 1996) and Aspergillus fumigatus (Girardin et al., 1993) based on Southern blot hybridization with complex DNA probes which fulfilled these requirements. They involved, in each case, two alternative fingerprinting probes, each containing an unrelated, moderately repetitive DNA sequence for cross-verification purposes. Here, we have applied a similar strategy in the development of a fingerprinting system for C. glabrata. Seven species-specific DNA probes were cloned from a genomic library of $C$. glabrata. Each generated a complex pattern when used as a probe in Southern blots of endonuclease-digested genomic DNA of a variety of independent isolates. The probes cross-hybridized at high stringency to varying degrees, and hybridized to sequences distributed throughout the genome, but with some differences in chromosome location and/or intensity. The effectiveness of two of these probes in grouping related isolates and in analysing genetic distance was established by comparison with RAPD analysis, using a collection of 39 isolates of C. glabrata from unrelated hosts collected in continental Europe, Great Britain and the United States. The effectiveness of both probes in assessing microevolution was also tested in an analysis of five series of isolates from recurrent vaginitis patients.

\section{METHODS}

Isolates. The 39 C. glabrata isolates from unrelated hosts used in this study are listed in Table 1 . Sequential isolates from recurrent infections in four vaginitis patients are described in Table 2. Only one isolate of the dominant genotype of the isolates fingerprinted in each of these latter sets were entered into the collection in Table 1 . All isolates were stored at room temperature on YPD agar slants $[1.5 \%(\mathrm{w} / \mathrm{v})$ agar, $2 \%(\mathrm{w} / \mathrm{v})$ peptone, $2 \%(\mathrm{w} / \mathrm{v})$ glucose, $1 \%$ yeast extract $]$ or at $-80{ }^{\circ} \mathrm{C}$ in litmus-milk broth (100 g milk powder $\mathrm{l}^{-1}, 10 \mathrm{~g}$ Litmus $\left.\mathrm{QS} \mathrm{l}^{-1}\right)$. For DNA extraction, a sample of a storage isolate was streaked on YPD agar and incubated for $2 \mathrm{~d}$ at $30^{\circ} \mathrm{C}$. Fingerprinting probes were highly stable following limited subculturing or storage.
Isolation of moderately repetitive elements. A $\lambda$ phage genomic library was created from C. glabrata isolate 7549 (Table 1) as described previously for the cloning of moderately repetitive elements from other fungi (Soll, 1996; Soll et al., 1987; Joly et al., 1996; Girardin et al., 1993; Scherer \& Stevens, 1988). Briefly, $100 \mu \mathrm{g}$ C. glabrata genomic DNA was partially digested with Sau3AI, then size-fractionated in a glycerol gradient (Soll, 1996). Genomic DNA in the size range of 9-15 $\mathrm{kb}$ was ligated to the arms of $\lambda$ EMBL3, digested with BamHI, and packaged using the Packagene kit as described by the manufacturer (Promega). The library was amplified in E. coli $\mathrm{P} 2392$ and plated at a density of 20000 plaques per $150 \mathrm{~mm}$ diameter Petri dish. Plaques were transferred in duplicate to nitrocellulose filters (Sambrook et al., 1989).

To probe the library for fragments containing repetitive elements, C. glabrata genomic DNA was partially digested with Sau3AI and TaqI to give a mean size fragment of 500-1000 bp. The genomic DNA fragments were labelled with ${ }^{32} \mathrm{P}$ by random priming (Sambrook et al., 1989) and used to probe one of the duplicate filters by the method of Church \& Gilbert (1984). By using a limiting amount of probe, repetitive elements gave stronger hybridization signals than unique elements and were picked for rescreening. The duplicate filter was hybridized with radiolabelled C. albicans rDNA (Srikantha et al., 1994) and compared with the filter hybridized with radiolabelled genomic DNA to eliminate plaques which contained ribosomal DNA inserts. All intensely hybridizing plaques which did not contain rDNA were rescreened by the same method and those that continued to show a strong signal were plaque-purified (Sambrook et al., 1989) and used as probes for Southern blots of EcoRI digested genomic DNA of two unrelated strains of C. glabrata as described below.

Southern blot hybridization and computer-assisted fingerprint analysis. Total genomic DNA from each C. glabrata isolate was prepared by the method of Scherer \& Stevens (1987). A total of $1 \cdot 2 \mu \mathrm{g}$ genomic DNA was digested with EcoRI and the resulting fragments electrophoresed for $15 \mathrm{~h}$ in a $1 \%(\mathrm{w} / \mathrm{v})$ agarose gel for the initial analysis of probes or in a $0.65 \%$ agarose gel for generating DNA fingerprinting patterns for computer-assisted analysis. DNA was transferred to a Nitropure membrane (MSI), hybridized with randomly primed ${ }^{32} \mathrm{P}$ labelled probe, and autoradiographed as previously described (Joly et al., 1996; Lockhart et al., 1996, Schröppel et al., 1994; Hellstein et al., 1993; Soll et al., 1991; Schmid et al., $1990,1993)$. Southern blots were then stripped of the initial radiolabel probe by shaking for $15 \mathrm{~min}$ in $85^{\circ} \mathrm{C}$ sterile water, rehybridized with a second probe and autoradiographed.

Autoradiographic images were digitized into the Dendron software package version 2.0 (Solltech, Iowa City, IA, USA) using a Scanjet II cx scanner (Hewlett-Packard) equipped with a transparency option. Each gel was processed for distortions, scanned and lanes and bands automatically identified. Similarity coefficients $\left(S_{\mathrm{AB}} \mathrm{s}\right)$ were computed for each pair of lanes (A and $\mathrm{B}$ ) based on band positions alone according to the formula $S_{\mathrm{AB}}=2 E /(2 E+a+b)$, where $E$ is the number of bands in patterns $\mathrm{A}$ and $\mathrm{B}$ sharing the same positions, $a$ is the number of bands in pattern A with no correlates in pattern B, and $b$ is the number of bands in pattern $B$ with no correlates in pattern $\mathrm{A}$. An $S_{\mathrm{AB}}$ of 0.00 indicates $\mathrm{A}$ and $\mathrm{B}$ patterns with no bands in common, and an $S_{\mathrm{AB}}$ of 1.00 indicates $\mathrm{A}$ and $\mathrm{B}$ patterns with all bands matching. Intermediary values from 0.01 to 0.99 represent increasing levels of pattern similarity. Dendrograms based on $S_{A B}$ values were generated using the unweighted pair group method (Sneath \& Sokal, 1973). For the combined dendrogram, the stored band data for the two 


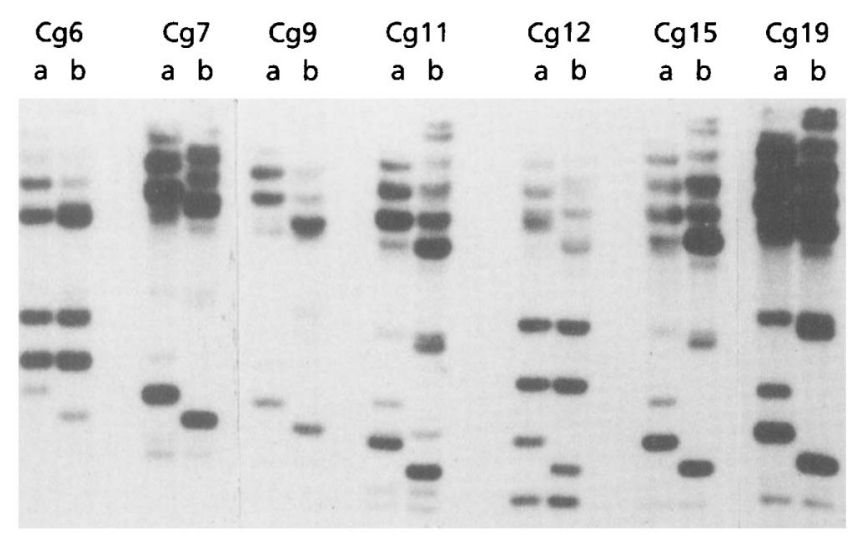

Fig. 1. All seven C. glabrata probes generate complex Southern blot hybridization patterns. Total genomic DNA from isolate J932405 (lanes a) or B63155 (lanes b) was digested with EcoRI and electrophoresed in a $0.8 \%$ agarose gel. The specific probes are indicated above each pair of blots.

probes were combined using Dendron software and the composite band data set used to create the dendrogram.

Setting a threshold for determining clusters in dendrograms is an arbitrary process. In past analyses, the mean $S_{A B}$ has been used as a threshold for collections of independent isolates (e.g. Pujol et al., 1997; Joly et al., 1996). More stringent $S_{\mathrm{AB}}$ s greater than $50 \%$ of the distance between the mean $S_{A B}$ and an $S_{A B}$ of 1.00 have been used to cluster highly related isolates (e.g. Lockhart et al., 1996). Here we have used relatively stringent $S_{A B}$ thresholds to define clusters in all dendrograms but the one in which the results with the $\mathrm{Cg} 6$ and $\mathrm{Cg} 12$ probes are combined. For each dendrogram, the threshold value used is discussed in the figure legend.

Karyotype analysis. Chromosomes were scparated by contour-clamped homogeneous electric field (CHEF) electrophoresis. To generate spheroplasts, C. glabrata was grown overnight at $37^{\circ} \mathrm{C}$, harvested, washed twice with sterile water and washed once with $1 \mathrm{M}$ sorbitol. The final cell peller was resuspended in a solution containing $1 \mathrm{M}$ sorbitol, $25 \mathrm{mM}$ EDTA and $50 \mathrm{mM}$ DTT, and incubated at room temperature for $20 \mathrm{~min}$. Cells were then pelleted and resuspended at a concentration of $1 \times 10^{9}$ cells ml $\mathrm{m}^{-1}$ in a solution containing $1 \mathrm{M}$ sorbitol, $0.1 \mathrm{M}$ sodium citrate, $\mathrm{pH} 5 \cdot 8,10 \mathrm{mM}$ EDTA and $0.4 \mathrm{mg}$ Zymolyase $100 \mathrm{~T} \mathrm{ml}^{-1}$ (Seikagaku America) at $37{ }^{\circ} \mathrm{C}$. Spheroplast formation was monitored at $600 \times$ magnification. Over $80 \%$ spheroplast formation was obtained after approximately $2 \mathrm{~h}$ incubation. Agarose plugs containing spheroplasts were generated by first dissolving $1 \mathrm{~g}$ agarose (Low Melt Preparative grade; Bio-Rad) in a prewarmed solution containing $10 \mathrm{mM}$ Tris $/ \mathrm{HCl}, \mathrm{pH} 8 \cdot 0$, and $0 \cdot 1 \mathrm{M}$ EDTA. The solution was cooled to $50^{\circ} \mathrm{C}$ and mixed $1: 1$ with the spheroplast suspension. This mixture was poured into plug moulds for the CHEF Mapper (Bio-Rad). The plugs were incubated in a solution containing $0.5 \mathrm{M}$ EDTA, $1 \% \mathrm{v} / \mathrm{v}$ Sarkosyl and $5 \mathrm{mg}$ Proteinase $\mathrm{K} \mathrm{ml}^{-1}$ for $72 \mathrm{~h}$ at $37^{\circ} \mathrm{C}$, then washed five times with a solution containing $10 \mathrm{mM}$ Tris/ $\mathrm{HCl}, \mathrm{pH} 7.6$, and $1 \mathrm{mM}$ EDTA, and stored at $4^{\circ} \mathrm{C}$ in the latter solution. The plugs were inserted in the CHEF Mapper and electrophoresed through a $1 \%(\mathrm{w} / \mathrm{v})$ agarose gel in a solution containing $22.5 \mathrm{mM}$ Tris $/ \mathrm{HCl}, 22.5 \mathrm{mM}$ botic acid and $1 \mathrm{mM}$ EDTA, pH 8.3. Electrophoresis was conducted with a twostep pulse time of 2 min at $4.5 \mathrm{~V} \mathrm{~cm}^{-1}$ for $20 \mathrm{~h}$, followed by a two-step pulse time of $3 \mathrm{~min}$ for an additional $20 \mathrm{~h}$ (Khattak et al., 1992). Following electrophoresis, the gel was stained with ethidium bromide, photographed and Southern blotted with a particular DNA probe (Sambrook et al., 1989).

RAPD analysis. A $500 \mu \mathrm{l}$ suspension of cells $\left(5 \times 10^{9}{\left.\text { cells } \mathrm{ml}^{-1}\right)}^{-1}\right.$ was mixed with an equal volume of glass beads $(0.45 \mathrm{~mm}$ diameter) and disrupted in a bead beater (Biospec Products). SDS was added to a final concentration of $2 \%(w / v)$ and the DNA purified by phenol/chloroform extraction. After precipitation in ethanol, the DNA was resuspended in Tris/ EDTA buffer ( $\mathrm{pH} \mathrm{8-0)}$. PCR were performed in $0.5 \mathrm{ml}$ microcentrifuge tubes containing $25 \mu \mathrm{l}$ of the following reaction mixture: $1 \mathrm{ng} C$. glabrata $\mathrm{DNA}, 2.5 \mu \mathrm{l} 10 \times$ buffer provided by the manufacturer for Taq DNA polymerase, $1.5 \mathrm{U}$ Taq DNA polymerase (Boehringer Mannheim), $200 \mu \mathrm{M}$ cach dATP, dCTP, dGTP and dTTP (Bochringer Mannheim) (a)

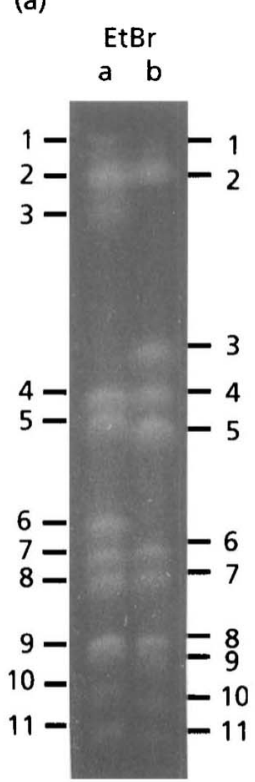

(b)

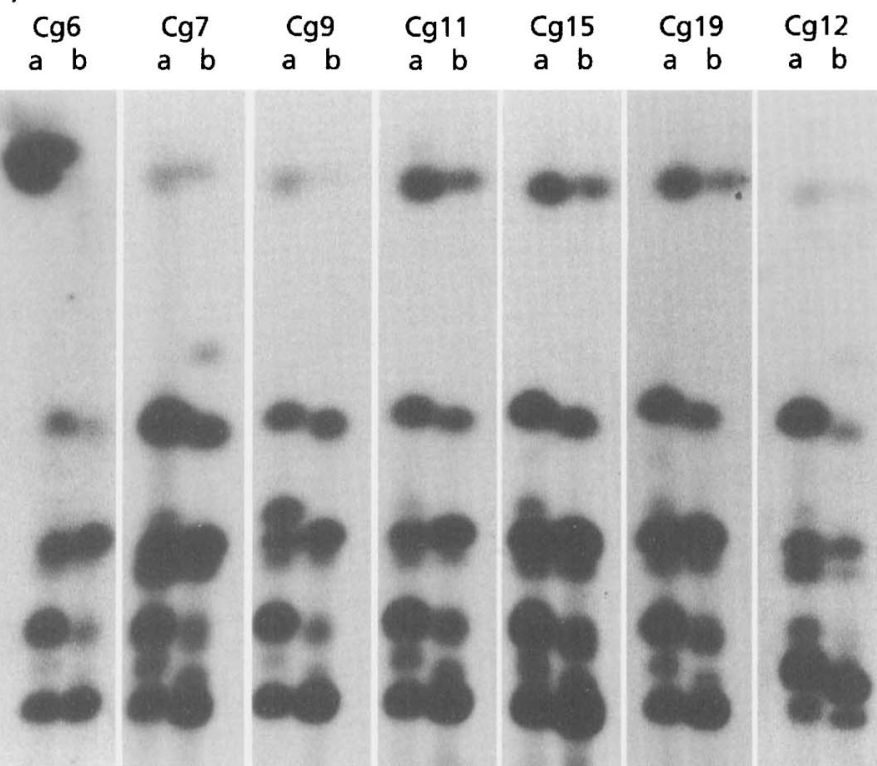

Fig. 2. Chromosomal distribution of the seven C. glabrata probes. Chromosomes of strains 7549 (lanes a) and 1942007 (lanes b) were separated by CHEF. (a) Ethidiumbromide-stained gel. The numbers to the left of 7549 and to the right of $J 942007$ indicate the assigned chromosome numbers used in this analysis. (b) Southern blot analysis of CHEF-separated chromosomes probed with each of the indicated $C$. glabrata probes. The specific probes are indicated above each pair of blots. 
and $0.4 \mu \mathrm{M}$ of one of the primers listed below. The reaction mixture was overlaid with one drop of mineral oil, and amplification was performed in a thermal cycler (Lab-Line) programmed for 45 cycles of $1 \mathrm{~min}$ at $94^{\circ} \mathrm{C}, 2 \mathrm{~min}$ at $36{ }^{\circ} \mathrm{C}$, and 2 min at $73^{\circ} \mathrm{C}$. Amplification products were separated by electrophoresis in a $1.3 \%(\mathrm{w} / \mathrm{v})$ agarose gel and detected by staining with ethidium bromide. Thirty primers containing 10 bases were initially tested for their capacity to generate different patterns between two test strains, and the following nine which fulfilled this requirement were selected: OPE-18, ggactgcaga ; OPE-04, gtgacatgcc; OPA-01, caggcctta ; OPA02 , tgccgagctg; OPA-04, a atcgggctg; OPA-10, gtgatcgcag; OPA-12, tcggcgatag; OPA-16, agccagcgaa ; OPA-18, aggtgaccgt (Operon Technologies). For computing $S_{A B}$ s between pairs of isolates analysed by RAPDs, patterns were manually entered into band data files, and $S_{A B}$ s were computed based upon the combined proportion of matches (Pujol et al., 1997).

\section{RESULTS}

\section{Cloning moderately repetitive elements}

A genomic library of C. glabrata isolate 7549 was plated on six dishes, generating approximately 20000 plaques per dish. The library on each plate was then transferred to duplicate nitrocellulose filters and hybridized either with radiolabelled total genomic DNA from C. glabrata or with radiolabelled ribosomal DNA from $C$. albicans. Highly repetitive elements gave a stronger hybridization signal than single locus elements under the conditions employed (Scherer \& Stevens, 1988; Sadhu et al., 1991; Girardin et al., 1993; Joly et al., 1996; Soll, 1996) and, therefore, were readily identified. Out of approximately 120000 plaques screened, 19 gave strong hybridization signals with genomic DNA, but not with ribosomal DNA. Upon further screening of the 19 selected plaques, 10 continued to give a strong signal. The ten were plaque-purified, and DNA was prepared from each and used to probe Southern blots of EcoRIdigested genomic DNA of two unrelated strains of $C$. glabrata. Seven of the ten cloned probes generated Southern blot hybridization patterns in $0.8 \%(\mathrm{w} / \mathrm{v})$ agarose gels with both test strains which were relatively complex (i.e. contained more than four bands) and which differed between the two strains by enough bands to compute potentially meaningful similarity coefficients (Fig. 1). Each probe generated patterns containing bands that were common to both test strains and bands unique to one or the other test strain. The patterns generated by the seven different clones for either test strain also exhibited similarities, suggesting that the seven clones may contain one or more common sequences. The approximate molecular masses (in $\mathrm{kb}$ ) of the seven clones were as follows: $\mathrm{Cg} 6,14 \cdot 8 ; \mathrm{Cg} 7,12 \cdot 5 ; \mathrm{Cg} 9,15 \cdot 2$; $\mathrm{Cg} 11,14 \cdot 3 ; \mathrm{Cg} 12,9 \cdot 0 ; \mathrm{Cg} 15,10 \cdot 3 ; \mathrm{Cg} 19,9 \cdot 0$.

To test further the relatedness of the seven probes, the cloned DNA in each recombinant phage was digested with Sall and EcoRI, electrophoresed in a $1.0 \%(\mathrm{w} / \mathrm{v})$ agarose gel for $4 \mathrm{~h}$ and the resulting Southern blot probed consecutively with each of the seven radiolabelled probes. Excluding common $\lambda$ arms at $>20$ and at $9.4 \mathrm{~kb}$, and undigested $i$ DNA above the $\lambda$ arm DNA, (a) $\mathrm{Cg} 6$

$\begin{array}{lllllllllll}1 & 2 & 3 & 4 & 5 & 6 & 7 & 8 & 9 & 10 & 11\end{array}$

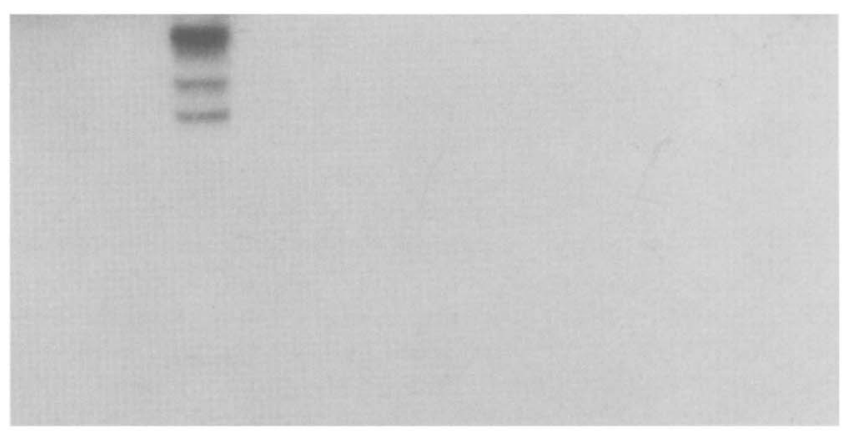

(b) $\mathrm{Cg} 11$

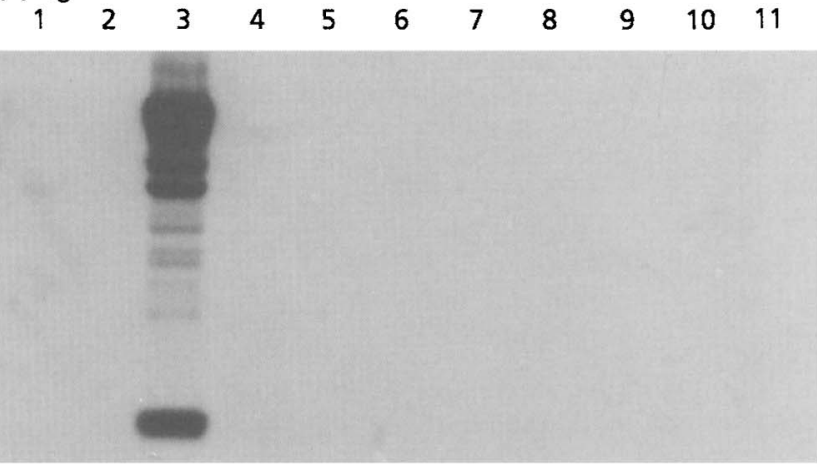

(c) $\operatorname{Cg} 12$

$\begin{array}{lllllllllll}1 & 2 & 3 & 4 & 5 & 6 & 7 & 8 & 9 & 10 & 11\end{array}$

Fig. 3. $\mathrm{Cg} 6, \mathrm{Cg} 11$ and $\mathrm{Cg} 12$ are species-specific for $C$. glabrata. Total DNA from 11 yeast species, indicated above each lane, was digested with ECORI, electophoresed in a $1 \%$ agarose gel, Southern blotted and hybridized at low stringency to radiolabelled probe DNA. Lanes: 1, Candida albicans; 2, Candida famata; 3, Candida glabrata; 4, Candida guillermondii; 5. Candida kefyr; 6. Candida krusei; 7, Candida lusitaniae; 8 , Candida parapsilosis; 9, Saccharomyces cerevisiae; 10, Candida tropicalis; 11, Trichosporon beigii.

all seven clones gave a unique restriction digest profile (data not shown), suggesting that they originated from different genomic sites and/or represented partial overlaps of the same site. When this Southern blot was consecutively probed with the seven different probes, there was cross-hybridization to varying degrees (data not shown). Under the stringent conditions employed, Cg12 did not seem to cross-hybridize with the other six 
Table 1. Origin of C. glabrata isolates used in this analysis

All isolates in the collection were verified as C. glabrata by sugar assimilation profiles and each was recovered from a separate individual. US cities: Iowa City, IA; Richmond, VA; Detroit, MI. NA, Information not available.

\begin{tabular}{|c|c|c|c|c|}
\hline Isolate & $\begin{array}{c}\text { Date } \\
\text { isolated }\end{array}$ & $\begin{array}{l}\text { Country or US } \\
\text { city of origin }\end{array}$ & Body location & $\begin{array}{l}\text { Type of } \\
\text { patient }\end{array}$ \\
\hline B63155 & $11 / 90$ & Belgium & Stool & Vaginitis \\
\hline J942007 & $11 / 94$ & Belgium & $\mathrm{NA}$ & NA \\
\hline J941814 & $10 / 94$ & Netherlands & Blood & Neutropenic \\
\hline J932387 & $11 / 93$ & Belgium & Anus & Vaginitis \\
\hline J932436 & $11 / 93$ & Belgium & Vagina & Vaginitis \\
\hline J932405 & $11 / 93$ & Belgium & Vagina & Vaginitis \\
\hline J932474 & $11 / 93$ & Belgium & Vagina & Vaginitis \\
\hline J932597 & $12 / 93$ & Belgium & Vagina & Vaginitis \\
\hline J931010 & $4 / 93$ & Germany & Oral & AIDS \\
\hline J932258 & $10 / 93$ & Germany & Oral & AIDS \\
\hline J932273 & $10 / 93$ & Germany & Oral & AIDS \\
\hline J932277 & $10 / 93$ & Germany & Oral & AIDS \\
\hline J932283 & $10 / 93$ & Germany & Oral & AIDS \\
\hline J932285 & $10 / 93$ & Germany & Oral & AIDS \\
\hline LY240 & NA & Great Britain & NA & NA \\
\hline LY241 & NA & Great Britain & NA & NA \\
\hline LY243 & NA & Great Britain & NA & NA \\
\hline LY358 & NA & Great Britain & NA & NA \\
\hline 1790 & NA & Germany & Stool & Vaginitis \\
\hline L-6 & $12 / 93$ & Iowa City & Vagina & Vaginitis \\
\hline 7549 & NA & Iowa City & $\mathrm{NA}$ & $\mathrm{NA}$ \\
\hline 1480.41 & 1995 & Richmond & Oral & AIDS \\
\hline 1480.42 & 1995 & Richmond & Oral & AIDS \\
\hline 1480.43 & 1995 & Richmond & Oral & AIDS \\
\hline 1480.44 & 1995 & Richmond & Oral & AIDS \\
\hline 1480.45 & 1995 & Richmond & Oral & AIDS \\
\hline 1480.46 & 1995 & Richmond & Oral & AIDS \\
\hline 1480.47 & 1995 & Richmond & Oral & AIDS \\
\hline 1480.49 & 1995 & Richmond & Oral & AIDS \\
\hline 1480.50 & 1995 & Richmond & Oral & AIDS \\
\hline LA817 & $11 / 88$ & Detroit & Vagina & Vaginitis \\
\hline LA701 & $9 / 90$ & Detroit & Vagina & Vaginitis \\
\hline RA732 & $9 / 90$ & Detroit & Vagina & Vaginitis \\
\hline NB783 & $11 / 88$ & Detroit & Vagina & Vaginitis \\
\hline SB448 & $6 / 92$ & Detroit & Vagina & Vaginitis \\
\hline PB09 & $9 / 94$ & Detroit & Vagina & Vaginitis \\
\hline CD457 & $6 / 90$ & Detroit & Vagina & Vaginitis \\
\hline PB813 & $11 / 88$ & Detroit & Vagina & Vaginitis \\
\hline LP688 & $10 / 88$ & Detroit & Vagina & Vaginitis \\
\hline
\end{tabular}

probes, even though its hybridization pattern in Fig. 1 indicates that it is most likely related to the other probes.

\section{Each probe identifies sequences dispersed throughout the majority of chromosomes}

To examine the distribution of probe sequences in the genome, the chromosomes of two unrelated isolates of C. glabrata, strain a $(7549$, which was used to generate the original C. glabrata library), and strain b (J942007, from Belgium), were separated by CHEF and Southern blots were hybridized with each of the probes. The chromosomes of both isolates separated into 11 distinguishable bands in ethiduim-bromide-stained gels; however, there were several differences in band sizes (Fig. 2a). This is comparable to the number of chromosomes distinguished by Kaufmann \& Merz (1989) and Khattak et al. (1992). The seven probes exhibited minor variations in their hybridization patterns to the chromosomes of either test strain (Fig. 2b). All probes hybridized to chromosomes $2,5,7,8,9,10$ and 11 of strain a and to chromosomes $2,5,6,7,9,10$ and 11 of strain b. All 
probes but Cg6 hybridized to chromosome 6 of strain a. There were also major differences in the intensity of hybridization between probes for specific chromosomes. However, the most striking aspect of the hybridization patterns was the general similarity for all seven probes. This similarity suggests that each probe shares at least one common sequence.

\section{The seven probes are species-specific}

To test the species-specificity of the probes, a Southern blot was prepared containing EcoRI-digested total genomic DNA from the following species: Candida albicans, Candida famata, Candida glabrata, Candida guillermondii, Candida kefyr, Candida krusei, Candida lusitaniae, Candida parapsilosis, Saccharomyces cerevisiae, Candida tropicalis and Trichosporon beigelii. The Southern blot was sequentially hybridized with the representative probes $\mathrm{Cg} 6$ (Fig. 3a), Cg11 (Fig. 3b) and Cg12 (Fig. 3c). Each probe hybridized exclusively to $C$. glabrata DNA. No hybridization signal was detected with any of the other ten species. In addition, a Southern blot of EcoRI-digested DNA of Candida (Torulopsis) castelii, a species with a sugar assimilation profile very similar to C. glabrata (Meyer et al., 1984), showed no hybridization to any of the three probes (data not shown).

\section{Cg6 and $\mathrm{Cg} 12$ each effectively discriminates unrelated isolates}

To test whether the cloned probes were effective in discriminating between unrelated isolates, DNA from 39 C. glabrata isolates collected from presumably unrelated hosts in three continental European countries, Great Britain, and three cities in the United States (Table 1) were digested with EcoRI, electrophoresed in $0.65 \%$ $(\mathrm{w} / \mathrm{v})$ agarose gels, and the resulting Southern blots consecutively hybridized with the radiolabelled probes $\mathrm{Cg} 6$ and $\mathrm{Cg} 12$ (Fig. 4). Cg6 and $\mathrm{Cg} 12$ were selected as representative probes because the Southern blot hybridization patterns they generated were the most diverse in the initial screen and contained at least one invariant band, making them more amenable to computer analysis. The two probes also exhibited the least amount of cross-hybridization. In Fig. 4, hybridization patterns are presented for 15 different isolates probed with $\mathrm{Cg} 6$ and $\mathrm{Cg} 12$. The first and last lanes of the gel contained the marker strain 7549 for normalization in computerassisted analysis. Fourteen unique patterns could be distinguished with $\mathrm{Cg} 6$ or $\mathrm{Cg} 12$, in which the patterns differed by the position of one or more bands. Isolates J932273 and J932288 gave identical hybridization patterns with both probes, but since both were isolated from HIV-positive patients in the same hospital at the same time, there was a higher probability that they were epidemiologically related and, in fact, represented the same strain. The discriminatory power of both $\mathrm{Cg} 6$ and $\mathrm{Cg} 12$ based on the 15 isolates (excluding J932288) in Fig. 4 was $100 \%$, and based on the 39 isolate collection in Table 1 was $100 \%$.

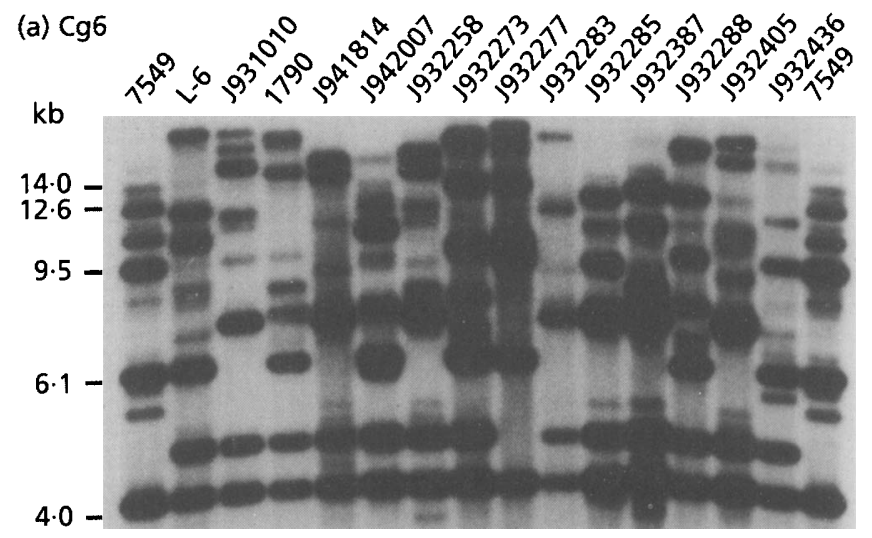

(b) $\mathrm{Cg} 12$

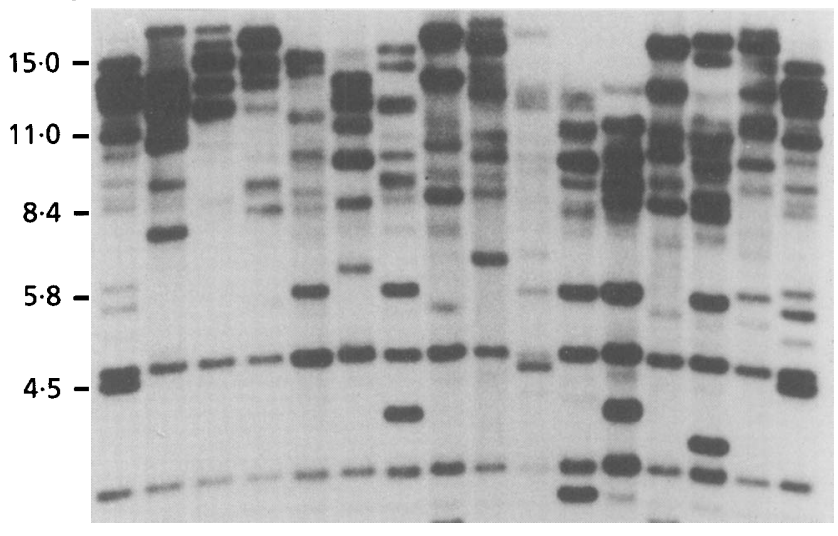

Fig. 4. Southern blot hybridization patterns of EcoRI-digested DNA from 15 isolates of C. glabrata (indicated above each lane) probed with either $\mathrm{Cg} 6$ (a) or $\mathrm{Cg} 12$ (b). DNA was electophoresed in a $0.65 \%$ agarose gel. Molecular masses in $\mathrm{kb}$ are indicated at the left of each gel. Note that the reference strain 7549 was run in both outer lanes to normalize the gel during computer-assisted analysis.

Each probe also gave identical hybridization patterns for the same strain on the same gel or on different gels. This is evident for the patterns of the marker strain 7549 run in the first and last lane of the gel in Fig. 4 and in Fig. 9. Probe $\mathrm{Cg} 6$ hybridized to between 9 and 16 different bands per isolate, while probe $\mathrm{Cg} 12$ hybridized to between 7 and 11 different bands per isolate. Both probes hybridized to at least one highly invariant band, at $4.0 \mathrm{~kb}$ in the case of $\mathrm{Cg} 6$ and at $4.5 \mathrm{~kb}$ in the case of $\mathrm{Cg} 12$. Invariant bands provide landmarks which facilitate normalization and unwarping procedures in automatic computer-assisted analyses of DNA fingerprints (Soll, 1993, 1996).

\section{Cg6 and Cg12 group independently collected isolates in a similar fashion}

To test whether the isolated probes group independently collected isolates in a similar fashion (i.e. provide similar measures of genetic distance for the same epidemiologically unrelated isolates), similarity coefficients based on band positions alone were computed between all pairs 
(a) $\mathrm{Cg} 6$

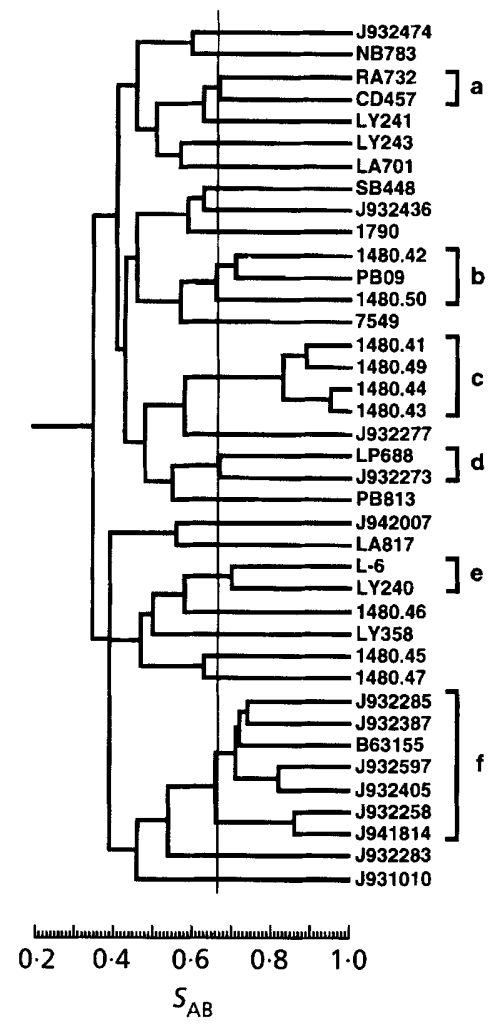

(b) $\mathrm{Cg} 12$

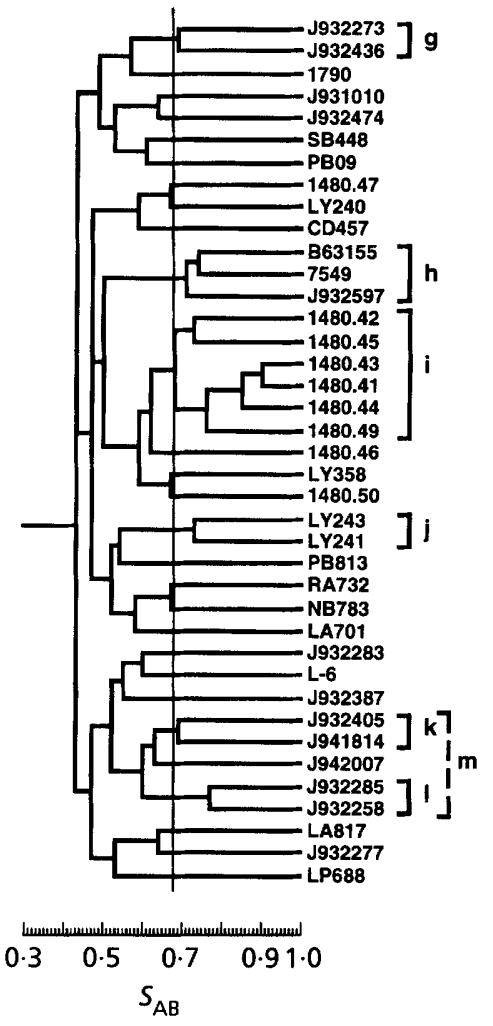

Fig. 5. Dendrogram of 39 independent isolates of C. glabrata (see Table 1) generated from the similarity coefficients $\left(S_{A B} s\right)$ computed for all possible pairs. Probed with $\mathrm{Cg} 6$ (a) or $\mathrm{Cg} 12$ (b). The main clusters, demarcated to the right of each dendrogram by solid lines, were based on arbitrary $S_{A B}$ thresholds of 0.67 and 0.68 for the $\mathrm{Cg} 6$ and $\mathrm{Cg} 12$ dendrograms, respectively. The stringency thresholds were 45 and $40 \%$, respectively, the distance from the mean $S_{A B}$ to an $S_{A B}$ of 1.00. A weak cluster $(m)$ is demarcated by a dashed line. of the 39 test isolates fingerprinted with the representative probes $\mathrm{Cg} 6$ and $\mathrm{Cg} 12$. The $S_{\mathrm{AB}}$ values were then used to generate dendrograms for the $\mathrm{Cg} 6$ and the $\mathrm{Cg} 12$ patterns (Fig. 5). If the two probes measure genetic distance in a similar fashion, then the clustering of independent isolates in the individual dendrograms will be similar.

The mean $S_{\mathrm{AB}}$ for the 39 isolates fingerprinted with $\mathrm{Cg} 6$ was $0 \cdot 40 \pm 0 \cdot 14$ and that for $\operatorname{Cg} 12$ was $0 \cdot 47 \pm 0 \cdot 11$. The similar mean $S_{\mathrm{AB}} \mathrm{s}$ and the low standard deviations ( 35 and $23 \%$ of the mean, respectively) suggest that both probes have similar discriminatory capabilities and both have evaluated the test population as reasonably unrelated. To assess whether the two probes clustered the 39 test isolates in a similar fashion, thresholds of 0.67 and 0.68 were respectively used to define clusters in the $\mathrm{Cg} 6$ and $\mathrm{Cg} 12$ dendrograms (Fig. 5). In the Cg6 dendrogram, six clusters $(a-f)$ were resolved. Clusters a, $d$ and $e$ included only two members each. However, clusters $c$ and $f$ included four and seven members, respectively. In the case of cluster $c$, all four isolates were from the same geographical locale (Richmond, VA, USA), and in the case of cluster $f$, all were from the same geographical locale (continental Europe). In the Cg12 dendrogram, five clusters $(\mathrm{g}-\mathrm{l})$ were resolved. Clusters $\mathrm{g}, \mathrm{j}, \mathrm{k}$ and $\mathrm{l}$ included only two members each. All four represented pairs of isolates from the same geographical locale. Cluster $\mathrm{i}$ represented the largest $\mathrm{Cg} 12$ cluster, and included the same four Virginia isolates in cluster $\mathrm{c}$ of the $\mathrm{Cg} 6$ dendogram plus two additional Virginia isolates
(Fig. 5b). By generating a weak cluster (i.e. at a lower $S_{\mathrm{AB}}$ than the ascribed 0.68 threshold), five continental Europe isolates formed cluster $\mathrm{m}$ in the $\mathrm{Cg} 12$ dendrogram. Four of these five also grouped in the $f$ cluster of the $\mathrm{Cg} 6$ dendrogram. These results demonstrate that $\mathrm{Cg} 6$ and $\mathrm{Cg} 12$ tend to cluster independent isolates in a similar but not in an identical fashion, and in addition, there is some degree of geographic specificity for the clustering.

\section{Verification of $\mathrm{Cg} 6$ and $\mathrm{Cg} 12$ fingerprinting by RAPD analysis}

A key method for verifying that a fingerprinting system assesses genetic distance is to demonstrate that it generally clusters weakly related isolates in a fashion similar to that of an unrelated fingerprinting system (Soll, 1996; Lockhart et al., 1996; Joly et al., 1996; Pujol et al., 1997). Although we have demonstrated that Cg6 and $\mathrm{Cg} 12$ cluster independent isolates in a similar fashion, the use of the two probes for cross-verification may not be justified since, as noted, there are indications that they may share common repetitive elements. We, therefore, tested the efficacy of each by comparison with an RAPD analysis performed on the same collection of 39 independent isolates. Of the 30 primers tested, nine were selected which generated variable patterns. All amplifications were repeated twice to assure reproducibility. In the comparative analysis, only the major bands in the RAPD gels were used, since, as in past 
(a) A18

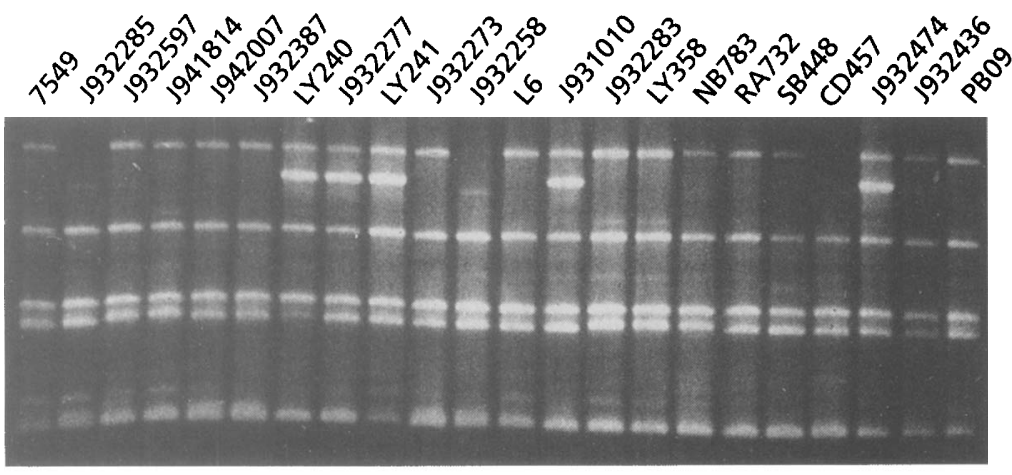

(b) E18

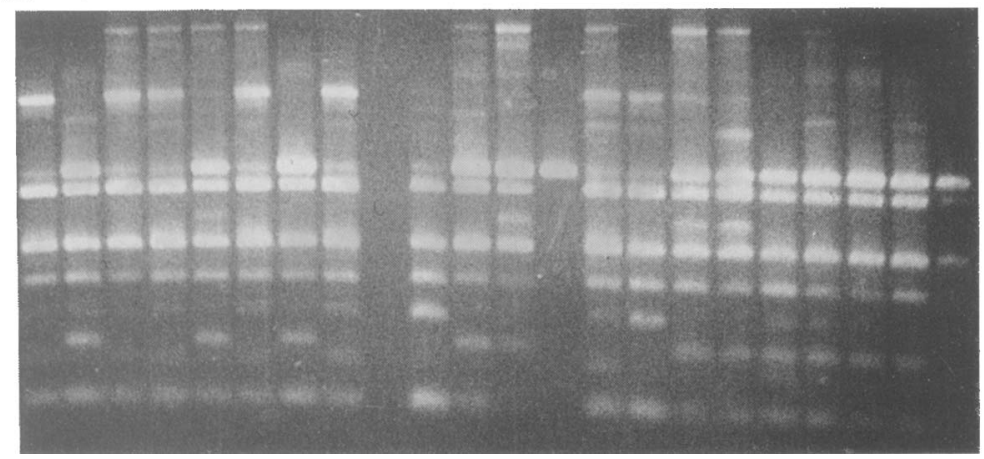

Fig. 6. Examples of RAPD patterns are presented for 21 C. glabrata isolates amplified with the primers OPA-18 (a) or OPE-18 (b). Only the major (most intense) bands were used in the analysis. studies (Pujol et al., 1997), minor bands were less reproducible. Examples of the patterns for two primers, OPA-18 and OPE-18, are presented in Fig. 6. Each of the eight selected primers provided one or more variable bands for the same collection of test isolates analysed with $\mathrm{Cg} 6$ and $\mathrm{Cg} 12$. Band positions in the RAPD patterns were manually entered into data files of the Dendron software package. A dendrogram was then generated based on the computed $S_{\mathrm{AB}}$ values (Fig. 7). The mean $S_{\mathrm{AB}}$ for the collection of test isolates was 0.66 , far higher than the mean $S_{\mathrm{AB}}$ s for $\mathrm{Cg} 6$ and $\mathrm{Cg} 12$. At a threshold of 0.87 , RAPDs separated the isolates into eight clusters $(n-v)$. The large number of strains grouped in clusters of two or more with $S_{\mathrm{AB}} \mathrm{s}$ of 1.0 demonstrated that this RAPD method provided less resolution than either $\operatorname{Cg} 6$ or $\operatorname{Cg} 12$ in distinguishing between independent isolates. Cluster v contained six isolates exclusively from continental Europe (Fig. 7). If the threshold for clustering in the RAPD dendrogram was relaxed to 0.76 , the $u$ and $v$ clusters combined into the $x$ cluster containing eight isolates, from central Europe. All seven of the isolates in cluster $\mathrm{f}$ of the Cg6 dendrogram (Fig. $5 a)$ were grouped in cluster $x$ of the RAPD dendrogram (Fig. 7). The RAPD dendrogram also grouped in cluster w (generated at a relaxed threshold) the same four isolates which were grouped in cluster c of the Cg6 dendrogram (Fig. 5a) and four of the six isolates grouped in cluster $i$ of the Cg12 dendrogram (Fig. 5b). Several additional similarities were evident in the clustering of isolates by RAPD, Cg6 and Cg12 when the threshold for clustering was relaxed in all three dendrograms. The comparable clustering of isolates in the test collection by RAPD, Cg6 and Cg12 cross-verifies the effectiveness of all in assessing the relatedness of independently isolated strains of C. glabrata, but shows superior resolution for Southern blot hybridization with the two probes.

\section{Mixing the information from $\mathrm{Cg} 6$ and $\mathrm{Cg} 12$ fingerprinting strengthens resolving power}

The capacity to assess differences between independent isolates is stronger for $\mathrm{Cg} 6$ and $\mathrm{Cg} 12$ fingerprinting than RAPD since the patterns generated by the two probes include bands representing mid-repeat sequences, which are usually more reorganizational than unique sequences. The majority of bands generated in the RAPD analysis more likely represent unique sequences in the genome, and variations between isolates, in this case, would be allelic. The effectiveness of a fingerprinting method depends, in part, on the complexity of the pattern generated for each strain and, more importantly, on the number of variable bands. The information from the separate banding patterns in the Cg6 and the $\mathrm{Cg} 12$ patterns of each strain was, therefore, combined using the Dendron program, and a dendrogram based on the combined information was generated (Fig. 8). If a cluster threshold was set at an $S_{\mathrm{AB}}$ of $0 \cdot 49$, the combined data in Cg6 and Cg12 generated a dendrogram in which eight of the nine isolates in the Richmond collection formed the single cluster $c^{\prime}$, which was penetrated by no other isolate in the collection. $\mathrm{Cg} 12$ alone clustered seven of this group of nine at a slightly reduced threshold, in 


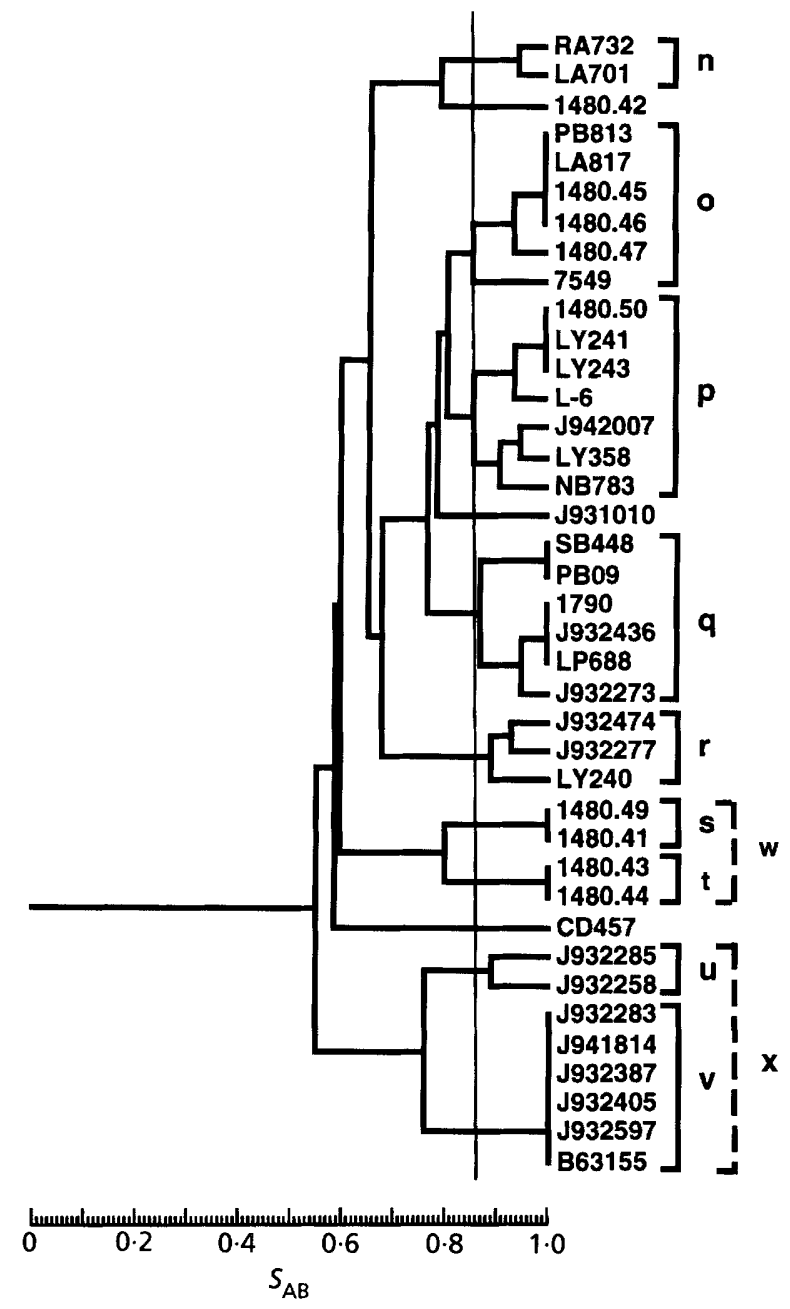

Fig. 7. Dendrogram of 39 independent isolates of C. glabrata (Table 1) generated on the $S_{A B}$ s computed from the combined data of RAPDs performed with the eight indicated primers. The main clusters $(n-v)$ indicated by solid lines to the right of the dendrogram were based on an arbitrary $S_{A B}$ threshold of 0.86 . This stringency threshold was $40 \%$ of the distance from the mean $S_{A B}$ to an $S_{A B}$ of 1.00. Weaker clusters ( $w$ and $x$ ) are demarcated by dashed lines.

cluster i (Fig. 5a), and Cg6 alone clustered only four, in cluster $\mathrm{c}$ (Fig. 5b). Combining the data also grouped the majority of the 15 isolates from continental Europe into two major clusters, the $\mathrm{e}^{\prime}$ cluster, which exclusively contained five of the isolates, and the $f^{\prime}$ cluster, which exclusively contained seven (Fig. 8). Only three continental Europe isolates did not fall in the two exclusive clusters. Cg6 grouped only seven of the 15 continental Europe isolates into the major cluster $\mathrm{f}$ (Fig. 5a), and only if the threshold for clustering was relaxed; Cg12 grouped only five into cluster m (Fig. 5b), but only when the threshold was reduced; and the RAPD analysis grouped only six into the major cluster $\mathrm{v}$ (Fig. 7). These results demonstrate that by combining the data from $\mathrm{Cg} 6$ and $\mathrm{Cg} 12$ fingerprinting, the capacity to cluster unrelated isolates from the same geographical locale
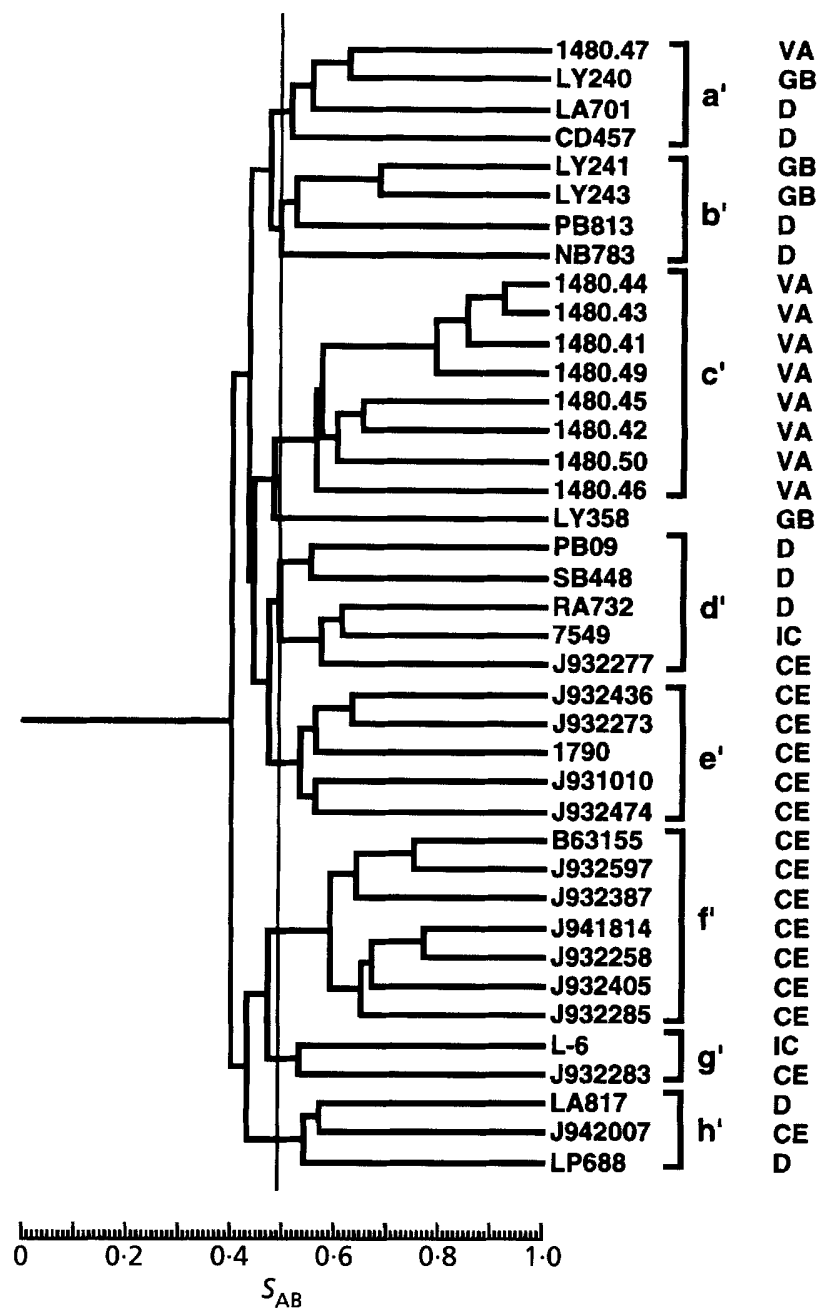

Fig. 8. Dendrogram of 39 unrelated C. glabrata isolates generated from the $S_{A B}$ values computed from the combined banding information of the $\mathrm{Cg} 6$ and $\mathrm{Cg} 12$ patterns of each isolate. The main clusters $\left(a^{\prime}-h^{\prime}\right)$ indicated to the right of each dendrogram by a solid line were based on the arbitrary $S_{A B}$ threshold of 0.49 . This threshold was not stringent since it was only slightly above the mean $S_{A B}$ of 0.45 . The geographical origin of each isolate is also indicated to the far right of the dendrogram. VA, Richmond, VA, USA; GB, Great Britain; D, Detroit, MI; CE, continental Europe; IC, lowa City, IA, USA.

increases beyond that obtained with a single fingerprinting probe or with the RAPD method applied here.

\section{Geographical specificity demonstrated in combined $\mathrm{Cg} 6$ and $\mathrm{Cg} 12$ dendrograms}

The combined Cg6-Cg12 dendrogram indicated strong geographical localization of strains. As noted, all but one of the nine isolates from Richmond grouped into the single cluster $\mathrm{c}^{\prime}$ (Fig. 8). This cluster was deemed tight since no other strain in the analysis penetrated it. In addition, all but three of the 15 isolates collected from continental Europe, which included strains from a variety of anatomical locations, grouped into two 
(a) Cg6
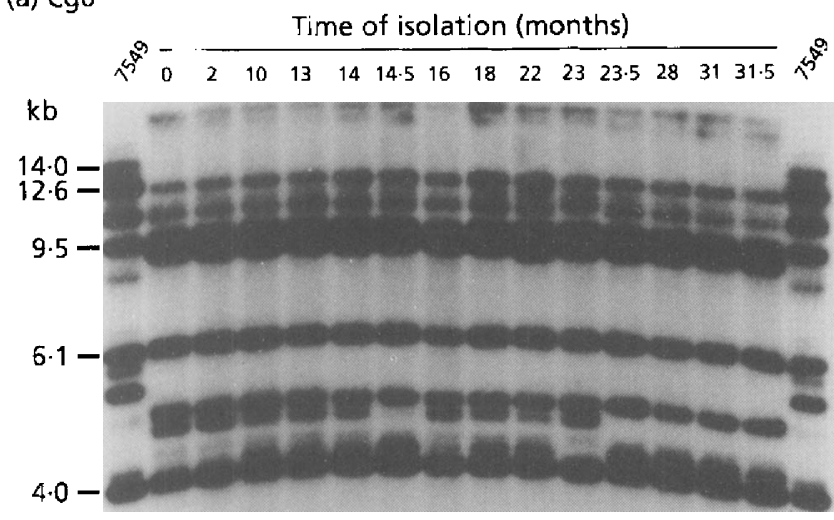

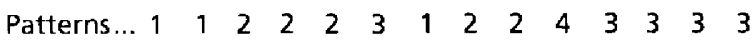

(b) $\operatorname{Cg} 12$
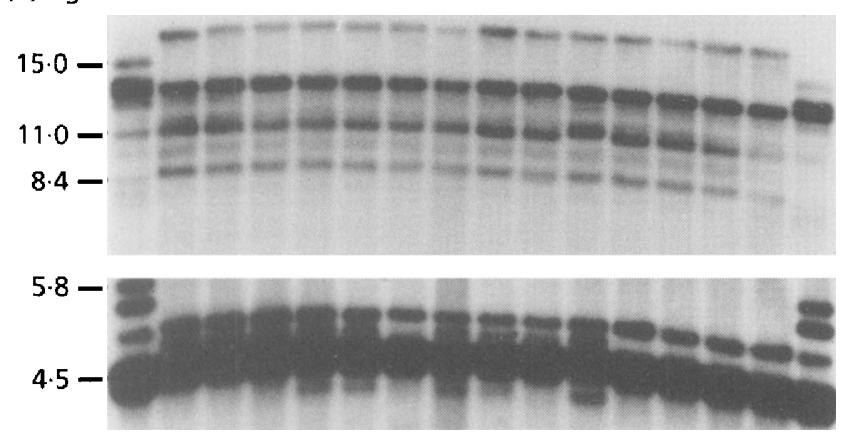

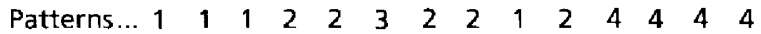

Fig. 9. Southern blot hybridization patterns of sequential isolates from a vaginitis patient (RA) probed with either $\mathrm{Cg} 6$ (a) or $\mathrm{Cg} 12$ (b). The variation in pattern is indicated at the bottom of each blot. Varying patterns are numbered in chronological order of occurrence. Reference strain 7549 was run in the two outside lanes of the gel. Two different intensities of the $\mathrm{Cg} 12$ pattern are presented to highlight the microevolutionary changes taking place. clusters $\left(e^{\prime}, f^{\prime}\right)$. Again these two clusters were deemed tight since no other strain in the analysis penetrated them (Fig. 8). In contrast, the nine vaginitis isolates from Detroit were more diverse, separating into four clusters $\left(a^{\prime}, b^{\prime}, d^{\prime}, h^{\prime}\right)$ (Fig. 8). In each cluster, the Detroit isolates co-clustered with isolates from all other geographical locales (Fig. 8). The four isolates from Great Britain were also dispersed. These results suggest strong geographical localization for the isolates obtained from Richmond and continental Europe.

\section{Strain replacement, strain maintenance and microevolution of sequential isolates from recurrent infections demonstrated by $\mathrm{Cg} 6$ and $\mathrm{Cg} 12$ fingerprinting}

The preceding cluster analysis tested the effectiveness of the two representative probes $\mathrm{Cg} 6$ and $\mathrm{Cg} 12$ in grouping unrelated isolates and, therefore, in assessing genetic distance. An additional expectation of a fingerprinting system is the capacity to assess microevolution in clonal populations. Four sets of sequential isolates from individuals suffering from recurrent vaginitis were, therefore, fingerprinted with $\mathrm{Cg} 6$ and $\mathrm{Cg} 12$. The number of isolates in the five sets ranged from 8 to 23 , and the length of time for each collection ranged between 3 and 50 months (Table 2). In Fig. 9, an example is presented of a partial set of isolates from patient $\mathrm{RA}$ fingerprinted with $\mathrm{Cg} 6$ and $\mathrm{Cg} 12$, respectively. The interpreted changes in the pattern (patterns involving changes in one or more band positions or intensities are numbered in chronological order) are presented under the blot in Fig. 9 (a) and in Table 2. The Cg6 pattern for RA isolates at 0 and 2 months were identical (Fig. 9a). However, the pattern changed at 10 months with the appearance of an intense band with a molecular size slightly greater than $4.0 \mathrm{~kb}$. At 12 months, C. albicans was collected in a

Table 2. Microevolution and substrain shuffling of clonal populations of $C$. glabrata assessed in sequential isolates from recurrent vaginitis patients

Microevolutionary changes in the $\mathrm{Cg} 6$ and $\mathrm{Cg} 12$ pattern are indicated by pattern number, in chronological order. In the cases of transient colonization by $C$. albicans or $S$. cerevisiae, the respective abbreviation $C a$ or $\mathrm{Sc}$ is indicated. In the case of $C$. glabrata strain replacement in patient LA, the pattern of the first strain is designated ' $a$ ', and the patterns of the second strain, which underwent minor changes, both for $\mathrm{Cg} 6$ and $\mathrm{Cg} 12$ patterns, are designated by numbers in chronological order. Time of sample isolation $(t)$ in months is indicated in bold.

\begin{tabular}{|c|c|c|c|c|c|c|c|c|c|c|c|c|c|c|c|c|c|c|c|c|c|c|c|c|c|}
\hline Patient & Pattern & & & & & & & & & & & & ttern & sequ & & & & & & & & & & & \\
\hline \multirow[t]{3}{*}{ RA } & & $t \ldots$ & 0 & 2 & 10 & 12 & 13 & $13 \cdot 5$ & 14 & $14 \cdot 5$ & 16 & 18 & 22 & 23 & 26 & 28 & 31 & $31 \cdot 5$ & 32 & $32 \cdot 5$ & 35 & 36 & 38 & 43 & 47 \\
\hline & $\mathrm{Cg} 6$ & & 1 & 1 & 2 & $\mathrm{Ca}$ & 2 & $\mathrm{Ca}$ & 2 & 3 & 1 & 2 & 2 & 4 & 3 & 3 & 3 & 3 & 3 & 3 & 3 & 3 & 3 & 5 & 3 \\
\hline & $\mathrm{Cg} 12$ & & 1 & 1 & 1 & $\mathrm{Ca}$ & 2 & $\mathrm{Ca}$ & 2 & 3 & 2 & 2 & 1 & 2 & 4 & 4 & 4 & 4 & 4 & 4 & 4 & 4 & 4 & 5 & 4 \\
\hline \multirow[t]{3}{*}{ LA } & & $t \ldots$ & 0 & 1 & 4 & 13 & 21 & 22 & 23 & 24 & 25 & 26 & 28 & 31 & 37 & 38 & 39 & 40 & 41 & 50 & & & & & \\
\hline & $\mathrm{Cg} 6$ & & $S_{c}$ & a & $\mathrm{Sc}$ & $\mathrm{Sc}$ & $\mathrm{Sc}_{\mathrm{c}}$ & $\mathrm{Sc}$ & 1 & 1 & 1 & 1 & 1 & 1 & 1 & 1 & 2 & 1 & 1 & 1 & & & & & \\
\hline & $\mathrm{Cg} 12$ & & $\mathrm{Sc}$ & $\mathrm{a}$ & Sc & $\mathrm{Sc}$ & $5 c$ & Sc & 1 & 1 & 1 & 1 & 1 & 1 & 1 & 1 & 2 & 1 & 1 & 1 & & & & & \\
\hline \multirow[t]{3}{*}{$\mathrm{P} B$} & & $t \ldots$ & 0 & 10 & 13 & 14 & 21 & 24 & 24 & 26 & & & & & & & & & & & & & & & \\
\hline & $\mathrm{Cg} 6$ & & 1 & 2 & 1 & 3 & 3 & 3 & 3 & 3 & & & & & & & & & & & & & & & \\
\hline & $\mathrm{Cg}_{\mathrm{g}} 12$ & & 1 & 2 & 3 & 4 & 4 & 4 & 4 & 4 & & & & & & & & & & & & & & & \\
\hline \multirow[t]{3}{*}{ LP } & & $t \ldots$ & 0 & 12 & 14 & 1.6 & 1.8 & 20 & $2 \cdot 3$ & $2 \cdot 7$ & $3 \cdot 0$ & $3 \cdot 0$ & & & & & & & & & & & & & \\
\hline & $\mathrm{Cg} 6$ & & 1 & 1 & 1 & 1 & 1 & 1 & 1 & 1 & 1 & 1 & & & & & & & & & & & & & \\
\hline & $\mathrm{Cg} 12$ & & 1 & i & l & 1 & 1 & 1 & 1 & 1 & 1 & 1 & & & & & & & & & & & & & \\
\hline
\end{tabular}


recurrent episode (Table 2), but at 13 months, an isolate was collected with the same pattern as the isolate at 10 months (Fig. 9a, Table 2). At 13.5 months, C. albicans was again collected, and at 14 months, an isolate of $C$. glabrata was again collected with the same pattern as the isolate at 10 months. At 14.5 months, a major change in the pattern occurred, which included the loss of a band slightly larger than $4.0 \mathrm{~kb}$ and an increase in the intensity of a band at approximately $4.3 \mathrm{~kb}$ (Fig. 9a, Table 2). At 16 months, an isolate was obtained with the pattern observed in the isolates at 0 months, and at 18 and 22 months isolates were obtained with the pattern observed in the isolate obtained at 10 months. At 23 months there was a change in the pattern which included an increase in the intensity of the $4.3 \mathrm{~kb}$ band, loss of the band just larger than $4 \cdot 1 \mathrm{~kb}$ and an increase in the size of a high-molecular-mass band. At 23.5 months, the pattern returned to that of the 14.5 month isolate, and remained stable in isolates obtained between 28 and 38 months (Fig. 9a, Table 2). At 43 months, a single band difference occurred and at 47 months, the pattern returned to that observed in the isolate at 10 months (Table 2). Therefore, sequential isolates from patient RA did not exhibit a smooth progressive change in the Cg6 pattern. Rather, there appeared to be substrain shuffling, which has previously been observed in sequential isolates of $C$. albicans from recurrent vaginitis patients (Lockhart et al., 1996). However, rough progression is evident in the absence of the 1 and 2 pattern in the last 14 months of sequential isolates (Table 2).

Roughly the same results were obtained when the sequential isolates from patient RA were fingerprinted with $\mathrm{Cg} 12$. There was both substrain shuffling and progression (Table 2, Fig. 9b). In addition, although there wasn't a firm correlation between the changes in Cg6 and Cg12 patterns over time, there was similar rough progression, suggesting that the $\mathrm{Cg} 6$ and $\mathrm{Cg} 12$ patterns undergo independent microevolution in parallel in clonal populations at sites of infection.

In an analysis of sequential isolates from recurrence patient LA, species replacement and strain replacement and substrain shuffling were observed (Table 2). The first LA isolate was $S$. cerevisiae, and the second, at 1 month, was C. glabrata. LA isolates at 4, 13, 21 and 22 months were again $S$. cerevisiae. The LA isolate at 23 months was again C. glabrata, but this isolate exhibited a $\mathrm{Cg} 6$ and $\mathrm{Cg} 12$ pattern distinctly different from that of the C. glabrata isolate collected at 1 month. The second C. glabrata strain was maintained between months 23 and 50 of the collection, with a transient, minor change in both the Cg6 and the Cg12 patterns at 39 months (Table 2). In an analysis of sequential isolates from a third recurrence patient $\mathrm{PB}$, progressive microevolution was observed in both the Cg6 and $\mathrm{Cg} 12$ patterns over time (Table 2). Finally, in an analysis of a fourth recurrence patient LP over a 3 month period, no change in pattern was observed (Table 2).

To demonstrate that sequential isolates of C. glabrata from recurrence patients (excluding isolate $a$ in the LA collection) were primarily clonal in origin, and to demonstrate the capacity of the two probes to cluster clonal collections, a dendrogram was generated based on the $S_{\mathrm{AB}} \mathrm{s}$ of $\mathrm{Cg} 6$ and another based on the $S_{\mathrm{AB}} \mathrm{s}$ of Cg12 patterns computed for all pairs in the combined collection of unrelated isolates in Table 1 plus recurrence isolates in Table 2. The entire set of RA isolates formed a highly related cluster, with the lowest connecting $S_{\mathrm{AB}}$ at 0.93 in both the $\mathrm{Cg} 6$ and $\mathrm{Cg} 12$ dendrograms (data not shown). No isolates from the other sequential collections or from the collection of 39 unrelated isolates grouped in the RA cluster in either the $\mathrm{Cg} 6$ or $\mathrm{Cg} 12$ dendrograms (data not shown). The entire set of $\mathrm{PB}$ isolates, the entire set of LP isolates and all but the first isolate in the LA collection also formed tight clusters in which absolutly no unrelated isolates co-grouped (data not shown). Together, the results obtained with the four sets of recurrence isolates demonstrate first that both $\mathrm{Cg} 6$ and $\mathrm{Cg} 12$ are excellent discriminators of relatedness between highly related isolates, and that both are sensitive indicators of microevolution within clonal populations of C. glabrata.

\section{DISCUSSION}

Although several alternative methods exist for fingerprinting the infectious fungi, Southern blot hybridization with complex DNA probes has proven to be one of the most effective since it fulfils many of the requirements for performing computer-assisted broad epidemiological studies. Such probes have previously been developed for C. albicans (Soll et al., 1987; Scherer \& Stevens, 1988; Sadhu et al., 1991), C. tropicalis (Joly et al., 1996) and A. fumigatus (Girardin et al., 1993), and in each of these cases, the effectiveness of the probes has been verified. Here, we have cloned and characterized potential DNA fingerprinting probes for the opportunistic yeast pathogen C. glabrata.

\section{Origin and relatedness of the seven probes}

Using a screen for genomic fragments that contain moderately repetitive sequences, seven probes were cloned which generated complex Southern blot hybridization patterns. The probes ranged between 9 and $15 \mathrm{~kb}$, and generated nonidentical hybridization patterns for the same test strain. Although nonidentical, the patterns generated by the individual probes shared striking similarities, suggesting that they contained common sequences. The probes cross-hybridized to varying degrees, but cross-hybridization accounted for a minority of the sequences in each probe. $\mathrm{Cg} 12$ exhibited the lowest level of cross-hybridization with the other six probes. These results suggest that the majority of probes share one or more common sequences, but contain predominantly unrelated sequences. Since the seven probes were cloned from a genomic library containing fragments from a partial Sau3AI digest, some may represent partially overlapping sequences. Alternatively, some may represent different genomic sequences containing common repetitive elements. The seven probes exhibit similar but nonidentical patterns of hybridization to the eleven chromosomes of C. glabrata 
separated by CHEF. In reference strain 7549 , no probe hybridized to chromosomes 1 and 4 . All probes hybridized to chromosomes $2,5,7,8,9,10$ and 11 of strain 7549 and to chromosomes $2,5,6,7,9,10$ and 11 of strain J942007. However, hybridization intensities varied dramatically between the seven probes for select chromosomes. In addition, only $\mathrm{Cg} 6$ did not hybridize to chromosome 6 of strain 7549, and only Cg7 and Cg12 hybridized to chromosome 3 of strain J942007. The most similar chromosome hybridization patterns were obtained with $\mathrm{Cg} 11, \mathrm{Cg} 15$ and $\mathrm{Cg} 19$ even though their restriction maps contained no common bands. These results support the conclusion that several of the probes originate from different genomic sites, but contain common sequences. Restriction mapping and selective sequencing of fragments from different probes will more definitively define the relationships of the seven probes.

\section{Verifying the effectiveness of the probes}

Probes Cg6, Cg11 and Cg12 were demonstrated to be species-specific. Each of the seven probes generated a complex pattern, with significant variability between unrelated isolates. The patterns were complex enough to compute meaningful similarity coefficients across a wide range of values. Both $\mathrm{Cg} 6$ and $\mathrm{Cg} 12$ differentiated all 39 unrelated isolates in the test collection, yet both identified sequential isolates from the same vaginitis patients as identical or highly related. Most importantly, both clustered isolates in the unrelated test collection in a similar but not identical fashion, suggesting that both probes were effective in assessing genetic distance between weakly related isolates. In previous characterizations of probes, we used two unrelated probes as well as other fingerprinting methods, including RAPD and multilocus enzyme electrophoresis, to cross-verify the capacity of probes to assess genetic distance (Lockhart et al., 1996; Girardin et al., 1993; Joly et al., 1996; Pujol et al., 1997). Such verification is based upon the premise that the molecular sequences upon which two unrelated fingerprinting methods are based will evolve independently. Therefore, if two methods effectively assess genetic distance, they should cluster weakly related isolates in a relatively similar but not identical fashion. Since there were indications that all seven cloned $C$. glabrata probes contained common repeat sequences, the use of two of these probes for cross-verification could be misleading. We, therefore, used the RAPD method to verify the capacity of $\mathrm{Cg} 6$ and $\mathrm{Cg} 12$ to assess genetic distance. Fifteen of the 39 isolates were grouped into comparable clusters by Cg6 and RAPD, and other additional similarities in clustering served to verify the effectiveness of both $\mathrm{Cg} 6$ and $\mathrm{Cg} 12$ in measuring the relatedness of independent isolates from different hosts. The information obtained from the RAPD patterns generated by nine primers was not as effective as either of the probes in discriminating between independent isolates. The RAPD analysis grouped more than half of the isolates with one or more other isolate at an $S_{\mathrm{AB}}$ of 1.0. Neither Cg6 nor Cg12 grouped any of the 39 independent isolates at an $S_{\mathrm{AB}}$ of $1 \cdot 0$.

\section{Combining fingerprinting information to increase resolution}

The capacity to discriminate between highly related isolates as well as the capacity to group weakly related isolates depends upon the information provided by a fingerprinting system. In the latter case, the resolving power for clustering increases as the complexity of information increases. We tested this prediction by combining the information obtained with the Cg6 and Cg12 probes. The combined information was more effective in generating geographically homogeneous clusters. Combining the information from different fingerprinting methods is readily performed when the information has been entered into a computer system in a compatible format, and should be considered in future fingerprinting studies.

\section{Geographical localization of strains}

There is growing evidence that strains of C. albicans can be geographically localized not only between continents (Clemons et al., 1997), but also between cities within a continent (Schmid et al., 1992; Lockhart et al., 1996; M. A. Pfaller and others, unpublished). In the collection of 39 independent C. glabrata isolates analysed here, fifteen were collected in continental Europe (Belgium, Netherlands, Germany), four in Great Britain, two in Iowa City, nine in Richmond, and nine in Detroit. In the combined $\mathrm{Cg} 6-\mathrm{Cg} 12$ dendrogram (Fig. 8), there was distinct clustering of the continental Europe isolates and of the Richmond isolates. In both of these cases, the collections were acquired in extremely short time windows of approximately 2 months. In contrast, the Detroit collection was obtained over a far longer time periods, which may explain their increased diversity. All nine Detroit isolates grouped into four clusters. No Richmond isolates co-clustered with a continental Europe isolate, and only three of the fifteen continental Europe isolates co-clustered with US isolates. These results demonstrate strong geographical localization of C. glabrata strains both between continents and between cities within a continent, just as in the case of $C$. albicans.

\section{Maintenance of strains, microevolution and substrain shuffling during recurrent vaginitis}

Clonal populations of $C$. albicans grown over many generations in vitro or which colonize a particular anatomical site undergo microevolution over time, and this has been monitored by Southern blot hybridization with the Ca3 probe (Scherer \& Stevens, 1988; Schmid et al., 1990, 1993; Lockhart et al., 1995, 1996; Schröppel et al., 1994), by Southern blot hybridization with the CARE2 probe (Lockhart et al., 1996) and by RAPD or multilocus enzyme electrophoresis (Pujol et al., 1997). Southern blot hybridization with DNA fingerprinting probes has also demonstrated microevolution in clonal populations of C. tropicalis (Joly et al., 1996) and Cryptococcus neoformans (Sullivan et al., 1996). We 
have demonstrated here that both the $\operatorname{Cg} 6$ and $\operatorname{Cg} 12$ probes discriminate microevolution in sequential isolates of C. glabrata obtained from recurrent vaginitis patients. Although multiple isolates from each episode were not fingerprinted, it is clear from the pattern analysis of sequential isolates that change can be progressive, although substrain shuffling does occur over prolonged periods of analysis. In two sets of sequential isolates, microevolution in both the $\mathrm{Cg} 6$ and Cg12 patterns occurred with time. However, the changes are not perfectly in parallel, suggesting that the hypervariable bands of these two probes do not represent identical sequences.

\section{Concluding remarks}

We have cloned and characterized DNA fragments from C. glabrata that fulfil all of the requirements for effective DNA fingerprinting probes. Each probe is speciesspecific and complex, and includes sequences which group weakly related isolates, and sequences which discriminate between highly related isolates (microevolution). The probes also contain invariant sequences which facilitate normalization in computer-assisted analysis. The capacity of two probes, $\mathrm{Cg} 6$ and $\mathrm{Cg} 12$, to group weakly related isolates has been verified by RAPD analysis, and the enhanced effectiveness of combining the information generated by the two probes has been demonstrated. These probes can now be used in large, computer-assisted epidemiological studies of this rapidly emerging pathogenic yeast.

\section{ACKNOWLEDGEMENTS}

The authors would like to thank Richard Barton and Frank Odds for providing isolates and Jennifer Fritch and Jason Stangl for early contributions to this work. The work was supported by Public Health Service grants AI2392 and DE10758 from the National Institutes of Health to D.R.S. S.R.L. was supported by training grant AG00214 from the National Institutes of Health.

\section{REFERENCES}

Asakura, K., Iwaguchi, S., Homma, M., Sukai, T., Higashide, K. \& Tanaka, K. (1991). Electrophoretic karyotypes of clinically isolated yeasts of Candida albicans and C. glabrata.J Gen Microbiol $25,31-38$.

Beck-Sague, C. \& Jarvis, W. R. (1993). Secular trends in the epidemiology of nosocomial fungal infections in the United States, 1980-1990. National Nosocomial Infections Surveillance System. J Infect Dis 167, 1247-1251.

Burgener-Kairuz, P., Zuber, J. P., Jaunin, P., Buchman, T. G., Bille, J. \& Rossier, M. (1994). Rapid detection and identification of Candida albicans and Torulopsis (Candida) glabrata in clinical specimens by species-specific nested PCR amplification of a cytochrome P-450 lanosterol-alpha-demethylase (L1A1) gene fragment. J Clin Microbiol 32, 1902-1907.

Church, G. M. \& Gilbert, W. (1984). Genomic sequencing. Proc Natl Acad Sci USA 81, 1991-1995.

Clemons, K. V., Feroze, F., Holmberg, K. \& Stevens, D. A. (1997). Comparative analysis of genetic variability among Candida albicans isolates from different geographic locales by three genotypic methods. J Clin Microbiol 35, 1332-1336.

Girardin, H., Latge, J. P., Srikantha, T., Morrow, B. \& Soll, D. R. (1993). Development of DNA probes for fingerprinting Aspergillus fumigatus. J Clin Microbiol 31, 1547-1554.

Hazen, K. C. (1995). New and emerging yeast pathogens. Clin Microbiol Rev 8, 462-478.

Hellstein, J., Vawter, H. H., Fotos, P., Schmid, J. \& Soll, D. R. (1993). Genetic similarity and phenotypic diversity of commensal and pathogenic strains of Candida albicans isolated from the oral cavity. J Clin Microbiol 31, 3190-3199.

Joly, S., Pujol, C., Schröppel, K. \& Soll, D. R. (1996). Development of two species-specific fingerprinting probes for broad computerassisted epidemiological studies of Candida tropicalis. J Clin Microbiol 34, 3063-3071.

Jordan, J. A. (1994). PCR identification of four medically important Candida species by using a single primer pair. J Clin Microbiol 32, 2962-2967.

Kaufmann, C. S. \& Merz, W. G. (1989). Electrophoretic karyotypes of Torulopsis glabrata. J Clin Microbiol 27, 2165-2168.

Khattak, M. N., Burnie, J. P., Matthews, R. C. \& Oppenheim, B. A. (1992). Clamped homogeneous electric field gel electrophoresis typing of Torulopsis glabrata isolates causing nosocomial infections. J Clin Microbiol 30, 2211-2215.

Lehmann, P. F., Lin, D. \& Lasker, B. A. (1992). Genotypic identification and characterization of species and strains within the genus Candida by using random amplified polymorphic DNA. $J$ Clin Microbiol 30, 3249-3254.

Lockhart, S. R., Fritch, J. J., Meier, A. S., Schröppel, K., Srikantha, S., Galask, R. \& Soll, D. R. (1995). Colonizing populations of Candida albicans are clonal in origin but undergo microevolution through $\mathrm{C} 1$ fragment reorganization as demonstrated by DNA fingerprinting and C1 sequencing. J Clin Microbiol 33, 1501-1509.

Lockhart, S. R., Reed, B., Pierson, C. \& Soll, D. R. (1996). The most frequent scenario for recurrent Candida vaginitis is strain maintenance with 'substrain shuffling': demonstrated by sequential DNA fingerprinting with probes Ca3, C1, and CARE2. J Clin Microbiol 34, 767-777.

Maiwald, M., Kappe, R. \& Sonntag, H. G. (1994). Rapid presumptive identification of medically relevant yeasts to the species level by polymerase chain reaction and restriction enzyme analysis. J Med Vet Mycol 32, 115-122.

Mason, M. M., Lasker, B. A. \& Riggsby, W. S. (1987). Molecular probe for identification of medically important Candida species and Torulopsis glabrata. J Clin Microbiol 25, 563-566.

Nguyen, M. H., Peacock, J. J., Morris, A. J., Tanner, D. C., Nguyen, M. L., Snydman, D. R., Wagener, M. M., Rinaldi, M. G. \& Yu, V. L. (1996). The changing face of candidemia: emergence of nonCandida albicans species and antifungal resistance. Am J Med $100,617-623$.

Pfaller, M. A. (1996). Nosocomial candidiasis: emerging species, reservoirs and models of transmisson. Clin Infect Dis 22 (suppl. 2), 589-594.

Pujol, C., Joly, S., Lockhart, S. R., Noel, S., Tibayrenc, M. \& Soll, D. R. (1997). Parity among the randomly amplified polymorphic DNA method, multilocus enzyme electrophoresis, and Southern blot hybridization with the moderately repetitive probe $\mathrm{Ca} 3$ for fingerprinting Candida albicans. J Clin Microbiol 35, 2348-2358.

Meyer, S. A., Ahearn, D. G. \& Yarrow, D. (1984). Candida Berkhout. In The Yeasts, pp. 585-884. Edited by N. J. Kreger-van Rij. Amsterdam: Elsevier.

Sadhu, C., McEachern, M. J., Rustchenko, B. E., Schmid, J., Soll, 
D. R. \& Hicks, J. B. (1991). Telomeric and dispersed repeat sequences in Candida yeasts and their use in strain identification. J Bacteriol 173, 842-850.

Sambrook, J., Fritsch, E. F. \& Maniatis, T. (1989). Molecular Cloning: a Laboratory Manual, 2nd edn. Cold Spring Harbor, NY : Cold Spring Harbor Laboratory.

Scherer, S. \& Stevens, D. A. (1987). Application of DNA typing methods to epidemiology and taxonomy of Candida species. J Clin Microbiol 25, 675-679.

Scherer, S. \& Stevens, D. A. (1988). A Candida albicans dispersed, repeated gene family and its epidemiologic applications. Proc Natl Acad Sci USA 85, 1452-1456.

Schmid, J., Voss, E. \& Soll, D. R. (1990). Computer-assisted methods for assessing strain relatedness in Candida albicans by fingerprinting with the moderately repetitive sequence $\mathrm{Ca} 3 . \mathrm{J}$ Clin Microbiol 28, 1236-1243.

Schmid, J., Odds, F. C., Wiselka, M. J., Nicholson, K. G. \& Soll, D. R. (1992). Genetic similarity and maintenance of Candida albicans strains from a group of AIDS patients, demonstrated by DNA fingerprinting. $J$ Clin Microbiol 30, 935-941.

Schmid, J., Rotman, M., Reed, B., Pierson, C. L. \& Soll, D. R. (1993). Genetic similarity of Candida albicans strains from vaginitis patients and their partners. J Clin Microbiol 31, 39-46.

Schröppel, K., Rotman, M., Galask, R., Mac, K. \& Soll, D. R. (1994). Evolution and replacement of Candida albicans strains during recurrent vaginitis demonstrated by DNA fingerprinting. J Clin Microbiol 32, 2646-2654.

Sneath, P. \& Sokal, R. (1973). Numerical taxonomy. In The Principles and Practice of Numerical Classification, pp. 230-234. San Francisco, CA: W. H. Freeman.

Sobel, J. D. (1996). Candida vulvovaginitis. Semin Dermatol 15, $17-28$.

Soll, D. R. (1993). DNA fingerprinting of Candida albicans, J Mycol Med 3, 37-44.

Soll, D. R. (1996). Computer-assisted analysis of DNA fingerprinting. In Genes and Genomes in Medically Important Fungi, pp. 97-108. Edited by K. Tanaka, Y. Yamaguchi \& P. T. Magee. Tokyo: Foundation for Advancement of International Science.
Soll, D. R., Langtimm, C. J., McDowell, J., Hicks, J. \& Galask, R. (1987). High-frequency switching in Candida strains isolated from vaginitis patients. J Clin Microbiol 25, 1611-1622.

Soll, D. R., Galask, R., Schmid, J., Hanna, C., Mac, K. \& Morrow, B. (1991). Genetic dissimilarity of commensal strains of Candida spp. carried in different anatomical locations of the same healthy women. J Clin Microbiol 29, 1702-1710.

Spinillo, A., Capuzzo, E., Egbe, T., Baltaro, F., Nicola, S. \& Piazzi, G. (1995). Torulopsis glabrata vaginitis. Obstet Gynecol 85, 993-998.

Srikantha, T., Gutell, R. R., Morrow, B. \& Soll, D. R. (1994). Partial nucleotide sequence of a single ribosomal RNA coding region and secondary structure of the large subunit $25 \mathrm{~s}$ rRNA of Candida albicans. Curr Genet 26, 321-328.

Sullivan, D., Bennett, D., Henman, M., Harwood, P., Flint, S., Mulcahy, F., Shanley, D. \& Coleman, D. (1993). Oligonucleotide fingerprinting of isolates of Candida species other than C. albicans and of atypical Candida species from human immunodeficiency virus-positive and AIDS patients. J Clin Microbiol 31, 2124-2133.

Sullivan, D., Haynes, K., Moran, G., Shanley, D. \& Coleman, D. (1996). Persistence, replacement, and microevolution of Cryptococcus neoformans strains in recurrent meningitis in AIDS patients. J Clin Microbiol 34, 1739-1744.

Vazquez, J. A., Beckley, A., Donabedian, S., Sobel, J. D. \& Zervos, M. J. (1993). Comparison of restriction enzyme analysis versus pulsed-field gradient gel electrophoresis as a typing system for Torulopsis glabrata and Candida species other than C. albicans. J Clin Microbiol 31, 2021-2030.

Voss, A., Kluytmans, J., Koeleman, J., Spanjaard, L., Vandenbroucke-Grauls, C., Verbrugh, H., Vos, M., Weersink, A., Hoogkamp-Korstanje, J. \& Meis, J. (1996). Occurrence of yeast bloodstream infections between 1987 and 1995 in five Dutch university hospitals. Eur J Clin Microbiol Infect Dis 15, 909-912.

Received 21 July 1997; revised 29 August 1997; accepted 8 September 1997. 